\title{
EAl Endorsed Transactions

\section{A Multi Criteria Decision Making Approach for the Selection of Optimum Location for Wind Power Project in India}

\author{
V. Manoj ${ }^{1, *}$, V. Sai Sravani ${ }^{2}$ and A. Swathi ${ }^{3}$ \\ ${ }^{1}$ Asst. Professor, Power Engineering Department, GMRIT, India \\ ${ }^{2}$ UG Scholar, Power Engineering Department, GMRIT, India \\ ${ }^{3} \mathrm{PG}$ Scholar, Mechanical Engineering Department, GMRIT, India
}

\section{Abstract}

This study tried to find out the selection of site for the wind turbine in India. We have chosen six wind power projects which are located different places in India. Wind power, Hub height, Distance, Cost, $\mathrm{CO}_{2}$, Wind speed and Blade height are the seven criteria had taken for the selection of best location. The analytical hierarchy process (AHP) is integrated with technique for order reference by similarity to ideal solution (TOPSIS) to meet the objective of this study. Firstly, the weights of each criterion are to determine using AHP. These weights will be used in TOPSIS method to select the best project. A case study is performed to exhibit the application of the methods was conducted to evaluate six types of wind power projects. The AHPTOPSIS result showed that the Muppandal wind farm, Kanyakumari is the best wind power project among the six projects.

Keywords: AHP, Energy, MCDM, Renewable Source, TOPSIS, Wind turbine selection

Received on 16 April 2020, accepted on 18 August 2020, published on 21 August 2020

Copyright $(0) 2020$ V. Manoj et al., licensed to EAI. This is an open access article distributed under the terms of the Creative Commons Attribution licence (http://creativecommons.org/licenses/by/3.0/), which permits unlimited use, distribution and reproduction in any medium so long as the original work is properly cited.

doi: 10.4108/eai.1-7-2020.165996

*Corresponding author. Email: manoj.v@gmrit.edu.in

\section{Introduction}

These days, ozone consumption, expanding worldwide normal temperature, environmental change, various kinds of contamination, and high reliance on petroleum products are some the significant issues confronting humankind. Clearly wellsprings of coal, oil, and gas will in the end evaporate within a reasonable time-frame. In this way, the expanded utilization of perfect and sustainable power sources is one of the measures that many created nations have taken in ongoing decades to handle these issues somewhat. The advancement of sustainable power source innovation and its going with benefits, for example, decreased contamination, plenitude, and changelessness have caused this sort of vitality, particularly wind vitality, to turn out to be financially reasonable and to be seen well by all specialists regarding this matter.

Wind, as other sustainable power sources, is geologically across the board and is quite often accessible; nonetheless, it is additionally scattered and decentralized and has a fluctuating and irregular nature. The Analytic Hierarchy Process (AHP), presented by Thomas Saaty (1980), is a compelling apparatus for complex decision making, and may help the chief to set needs and settle on the best choice. By decreasing complex choices to a progression of pairwise examinations, and afterward blending the outcomes, the AHP assists with catching both emotional and target parts of a choice. Likewise, the AHP consolidates a helpful strategy for checking the consistency 
of the chief's assessments, in this way lessening the predisposition in the dynamic procedure.

The paper is organized as follows: after the introduction and literature survey, Section 3 presents the methodology with mathematical formulation of the new MCDM method and the basic steps of the AHP and TOPSIS. The Section 4 presents results with an application of the AHP and TOPSIS calculations. The final section (Section 5) presents the conclusion. The aim of this paper is to choose the best project Windmill in India. Here six Windmills have been chosen as projects and seven criteria's for selection.

\section{Literature Review}

Sustainable power source is developing as an answer for a sustainable, environmentally well-disposed and long haul, savvy wellspring of vitality for what's to come. Sustainable power source choices are equipped for supplanting ordinary wellsprings of vitality in a large portion of their applications at serious long haul costs $[1,2]$. In spite of the fact that AHP is anything but difficult to utilize and apply, its unidirectional relationship trademark can't deal with the multifaceted nature of numerous issues. ANP, in any case, manages the issue as a system of complex connections among options and criteria where all the components can be associated. Cheng and $\mathrm{Li}$ an experimental guide to delineate utilization of ANP [3]. Begic and Afgan evaluated the options of energy power systems for Bosnia Herzegovina under a multi-criteria sustainability assessment framework in order to investigate options for the selection of new capacity building of this complex system [4].

Ivanova et al. surveyed the attainability of wind power plant development in an electric force framework utilizing a progressive multi-criteria approach [5]. Charnes, A et al., (1978) proposed a nonlinear (nonconvex) programming model which gives another meaning of effectiveness for use in assessing exercises of not-revenue driven substances taking an interest openly programs. Haworth, $\mathrm{N}$ et al., (2012) discussed about PTWs and will keep on developing as they assume a significant job in both vehicle and entertainment over the world. Their examples of utilization contrast notably between and among created and creating nations and this influences the wellbeing difficulties and portability openings that they speak to.Pamučar, D et al., (2015) indicated that the TOPSIS, MOORA, SAW, COPRAS and VIKOR techniques don't meet at least one conditions set, but the MABAC strategy demonstrated soundness in its answers. Through the exploration introduced right now, is indicated that the new MABAC technique for MCDM is a helpful and solid apparatus for rational decision-making.

Amer et.al., (2011) Utilized MCDM just because for the vitality area of Pakistan. Introduced AHP model for the choice and prioritization of different sustainable power source advances for power age. Wind vitality, sun based photovoltaic, sun oriented warm, and biomass vitality were utilized as choices. Martin et al. (2013) introduced a technique to assess various drifting help structure designs, for seaward wind turbines sent in profound waters. Datta et al. (2014) recognized the best islanding recognition strategy for a sunlight based photovoltaic framework by utilizing TOPSIS alongside other MCDM strategies. Kahraman et.al., (2010) executed a fuzzy MCDMmethod, in view of the AHP strategy, to locate the ideal among vitality strategies in Turkey.

\section{Methodology}

\section{Proposed Methodology for Optimum Solution:}

In order to find out the best wind power project out of 6 projects firstly we need to estimate the criteria weights using Analytical Hierarchy Process (AHP). Using these criteria weights, next we have to find out the rankings for all the projects using MCDM technique like TOPSIS [4]. Finally, we will rank the projects based on their performance score.

Seven criteria's which we had taken for selecting the best wind power project are given below:

Wind power: The amount of power generated is very important for any power project, the generated power should be more which is measured in Mega Watts (MW).

Hub height: The hub height is also another important criteria and had taken more the hub height higher is the power generated which is measured in Meters (m).

Distance: The distance from power plant to the grid should be less and it is measured in Meters (m).

Cost: For installing any power plant we should have sufficient funds or we have should invest money on it. So, the cost of plant is also plays an important role in establishment of a power plant which is measured in Crores.

CO2: By choosing renewable energy sources we can reduce the amount of $\mathrm{CO}_{2}$ emissions (million tonnes reduced) over Conventional sources.

Wind speed: The speed of the wind for the particular plant location should be more in order to generate more power and it is measured in meter/second.

Blade height: For any wind power project the blade height will also plays a key role in generation of power. Based on the rotation of the blade the turbine will rotate which in turn rotates the rotor of the generator. Here I have taken less blade is the best one which is measured in Meters (m). 


\subsection{Analytical Hierarchy Process (AHP)}

This method is used to calculate the weights of the criteria. It mainly involves 3 steps.

\section{Step 1:}

Firstly we have to develop a hierarchal structure shown in the below figure with the goal at the top level, the criteria at the second level and the projects at third level.

In this I am considering 6 Projects i.e., windmills and 7 Criteria's.

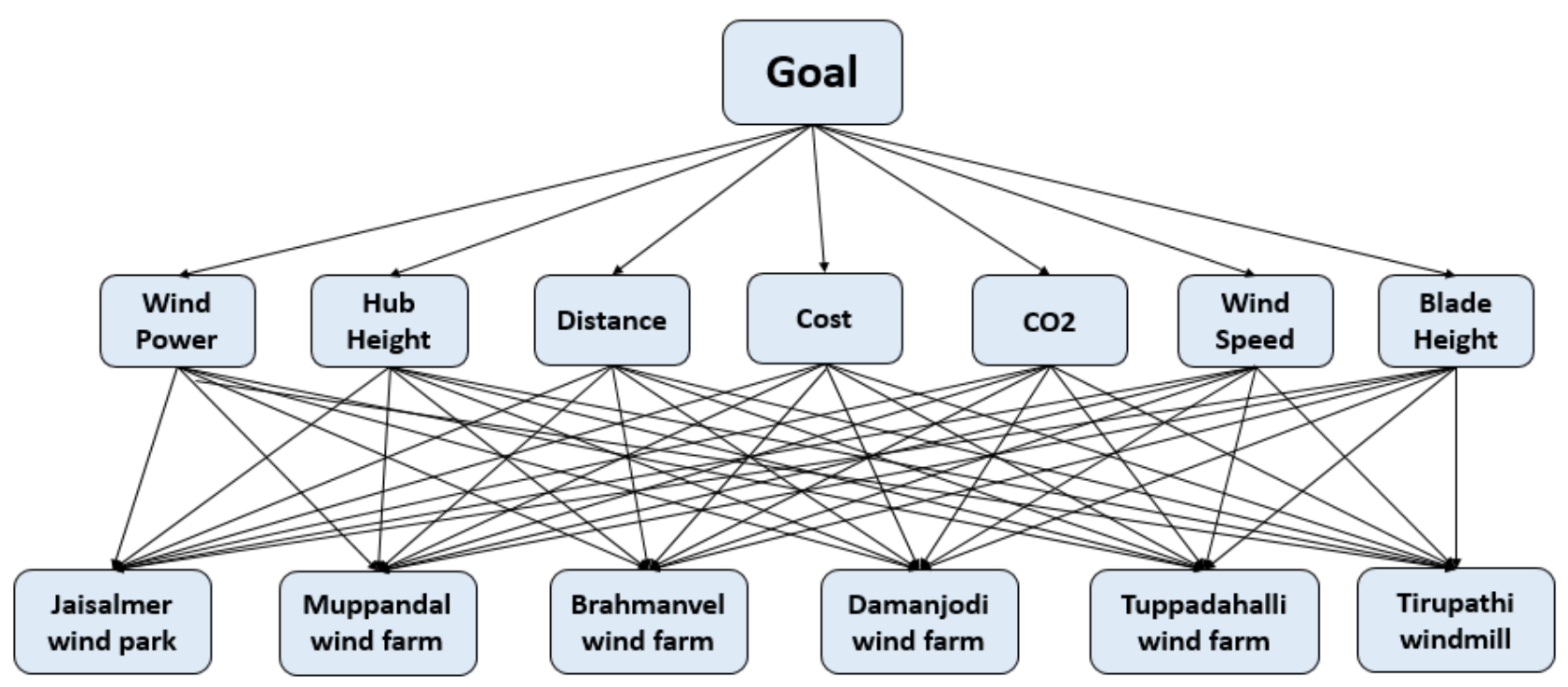

Figure 1. Decision Hierarchy

Step 2:

This step involves developing of pair wise comparison matrix.

Which is haing a matrix size of $7 * 7$ shown in Table 2 .

After that normalized pair wise comparison matrix has to be created which is shown in Table 3 .

Step 3:

Calculating the consistency matrix which is shown in Table 4.

Then weighted sum value is calculated by adding all the values in the particular row. After that ratio of weighted sum value to the criteria weight has to be calculated for each row.

Now, lambda max is calculated by taking the average of these values. Then consistency index is to be calculated. $\lambda=$ Weighted Sum Value / Criteria Weight

Using equation (1) the resulting value shown in Table 5

Consistency index $($ C.I $)=(\lambda \max -n) /(n-1)$

Consistency Ratio = C.I/ R.C.I

The consistency ratio is then calculated and the value of consistency ratio should be less than 0.1 . Then the obtained criteria weights are correct.

\subsection{TOPSIS Method}

Now, we were dealing the selection of best wind power project out of 6 projects. Criteria's are Wind power, Hub height, Distance, Cost, $\mathrm{CO}_{2}$, Wind speed and Blade height.
AHP - to estimate the criteria weights

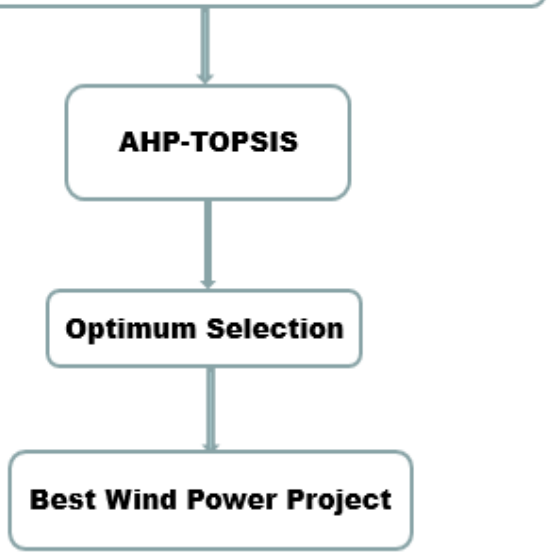

Figure 2. Step by Step procedure for selection of wind power project

The procedure of TOPSIS method is as follows:

Step 1: Construction of decision matrix:

It is the matrix formed between Projects and Criteria's and the size of the matrix is $6 * 7$.

Criteria's as $\mathrm{X}$-axis and Projects as $\mathrm{Y}$-axis. The decision matrix which is shown in Table 8

Step 2: Normalization of the evaluation matrix:

The determination of normalized values of projects $\mathrm{X}_{i j}$ : 


$$
\overline{X_{\imath \jmath}}=\frac{X_{i j}}{\sqrt{\sum_{i=1}^{n}\left(X_{i j}\right)^{2}}}, i=1,2, \ldots, \mathrm{m} ; j=1,2, \ldots, \mathrm{n} .
$$

Using equation (4) normalized decision matrix is shown in Table 9.

Step 3: Construction of the weighted normalized decision matrix:

It can be calculated by multiplying the normalized evaluation matrix $\mathrm{X}_{i j}$ with its associated weight $w_{j}$ (shown in Table 8) to obtain the result.

$$
V_{i j}=\bar{X}_{i j} \times W_{j}
$$

Using equation (5) weighted normalized decision matrix is shown in Table 10.

Step 4: Determination of the positive and negative ideal solutions:

$V_{i}^{+}$is maximum value as a best project for beneficial.

$V_{i}^{-}$is minimum value as a worst project for beneficial.

$V_{i}^{+} \& V_{i}^{-}$is shown in Table 11.

Step 5: Calculation of the Euclidean distance:

$$
\begin{gathered}
S_{i}^{+}=\sqrt{\sum_{j=1}^{m}\left(v_{i j}-v_{j}^{+}\right)^{2}} \\
S_{i}^{-}=\sqrt{\sum_{j=1}^{m}\left(v_{i j}-v_{j}^{-}\right)^{2}}
\end{gathered}
$$

Using equations (6) \& (7), $S_{i}^{+} \& S_{i}^{-}$is shown in Table 12.

Step 6: Calculating Performance score:

$$
P_{i}=\frac{S_{\bar{i}}^{-}}{S_{i}^{+}+S_{i}^{-}}
$$

Using equation (8) $P_{i}$ is shown in Table 13.

Step 7: Ranking the priority:

The ranking is made according to the descending order of Pi.

The project with more score will be ranked first.

\section{Results and Discussion}

\subsection{AHP Calculations}

The choice chain of importance chart is set up utilizing recognized assessment criteria and the elective mixes. The choice model comprises of three levels, specifically, the target of the issue, criteria and the other options, which are situated at the significant level, second level and the base level individually. After the development of the progressive system graph for the issue as referenced, the AHP strategy requires the pair-wise examination of the criteria so as to decide their relative loads. In the pair shrewd examination process, every paradigm is contrasted and others utilizing saaty's nine point scale [3]

Table 1. Nomenclature

\begin{tabular}{|l|l|}
\hline Criteria's & Wind Power Project \\
\hline CT1 - Wind power (MW) & WPP1 - Jaisalmer wind park, Rajasthan \\
CT2 - Hub height (m) & WPP2 - Muppandal wind farm, Kanyakumari \\
CT3 - Distance (m) & WPP3 - Brahmanvel wind farm, Maharashtra \\
CT4 - Cost (crores) & WPP4 - Damanjodi wind farm, Odisha \\
CT5 - CO2 (million tonnes reduced) & WPP5 - Tuppadahalli wind farm, Karnataka \\
CT6 - Wind speed (m/s) & WPP6 - Tirupathi windmill, Tirupathi \\
CT7 - Blade height (m) & \\
\hline
\end{tabular}

Firstly, we have to calculated the pair wise comparison matrix using seven criteria's which is of $7 * 7$ size. This matrix was completely depending upon scale of importance given from 1 to 9 . It will be variable for person to person.

Table 2. Comparison of pair-wise matrix

\begin{tabular}{|c|c|c|c|c|c|c|c|}
\hline Criteria's & CT1 & CT2 & CT3 & CT4 & CT5 & CT6 & CT7 \\
\hline CT1 & 1 & 0.5 & 0.5 & 0.333 & 0.333 & 0.5 & 0.25 \\
\hline CT2 & 2 & 1 & 0.25 & 0.333 & 0.5 & 0.333 & 0.333 \\
\hline CT3 & 2 & 4 & 1 & 0.25 & 0.333 & 0.333 & 0.25 \\
\hline CT4 & 3 & 3 & 5 & 1 & 2 & 0.5 & 0.333 \\
\hline CT5 & 3 & 2 & 3 & 0.5 & 1 & 0.5 & 0.333 \\
\hline CT6 & 2 & 3 & 3 & 2 & 2 & 1 & 0.5 \\
\hline CT7 & 4 & 3 & 4 & 3 & 2 & 2 & 1 \\
\hline
\end{tabular}


Table 3. Normalised Pair-wise matrix

\begin{tabular}{|c|c|c|c|c|c|c|c|}
\hline Criteria's & CT1 & CT2 & CT3 & CT4 & CT5 & CT6 & CT7 \\
\hline CT1 & 0.0588 & 0.0303 & 0.0299 & 0.0449 & 0.0408 & 0.0968 & 0.0834 \\
\hline CT2 & 0.1176 & 0.0606 & 0.0149 & 0.0449 & 0.0612 & 0.0645 & 0.1110 \\
\hline CT3 & 0.1176 & 0.2424 & 0.0597 & 0.0337 & 0.0408 & 0.0645 & 0.0834 \\
\hline CT4 & 0.1765 & 0.1818 & 0.2985 & 0.1348 & 0.2449 & 0.0968 & 0.1110 \\
\hline CT5 & 0.1765 & 0.1212 & 0.1791 & 0.0674 & 0.1225 & 0.0968 & 0.1110 \\
\hline CT6 & 0.1176 & 0.1818 & 0.1791 & 0.2697 & 0.2449 & 0.1936 & 0.1667 \\
\hline CT7 & 0.2353 & 0.1818 & 0.2388 & 0.4045 & 0.2449 & 0.3871 & 0.3334 \\
\hline
\end{tabular}

Table 4. Calculating the Consistency

\begin{tabular}{|c|c|c|c|c|c|c|c|}
\hline Criteria's & CT1 & CT2 & CT3 & CT4 & CT5 & CT6 & CT7 \\
\hline CT1 & 0.0550 & 0.0339 & 0.0459 & 0.0592 & 0.0416 & 0.0967 & 0.0724 \\
\hline CT2 & 0.1099 & 0.0678 & 0.0229 & 0.0592 & 0.0625 & 0.0644 & 0.0964 \\
\hline CT3 & 0.1099 & 0.2713 & 0.0917 & 0.0444 & 0.0416 & 0.0644 & 0.0724 \\
\hline CT4 & 0.1649 & 0.2035 & 0.4586 & 0.1778 & 0.2499 & 0.0967 & 0.0964 \\
\hline CT5 & 0.1649 & 0.1357 & 0.2752 & 0.0889 & 0.1249 & 0.0967 & 0.0964 \\
\hline CT6 & 0.1099 & 0.2035 & 0.2752 & 0.3555 & 0.2499 & 0.1934 & 0.1447 \\
\hline CT7 & 0.2199 & 0.2035 & 0.3669 & 0.5333 & 0.2499 & 0.3867 & 0.2894 \\
\hline
\end{tabular}

Table 5. Calculation of $\lambda$

\begin{tabular}{|c|c|c|c|}
\hline Criteria & $\begin{array}{c}\text { Weighted Sum } \\
\text { Value }\end{array}$ & $\begin{array}{c}\text { Criteria } \\
\text { Weights }\end{array}$ & $\boldsymbol{\lambda}$ \\
\hline CT1 & 0.40458 & 0.054972 & 7.359697 \\
\hline CT2 & 0.483131 & 0.06783 & 7.122707 \\
\hline CT3 & 0.695775 & 0.091726 & 7.585344 \\
\hline CT4 & 1.447715 & 0.177769 & 8.14381 \\
\hline CT5 & 0.982621 & 0.124927 & 7.86554 \\
\hline CT6 & 1.532069 & 0.193353 & 7.923693 \\
\hline CT7 & 2.249573 & 0.289423 & 7.772624 \\
\hline
\end{tabular}

$\lambda \max =$ Average Value of $\lambda=7.681916$

From equation (2),

Consistency index (C.I) $=0.113653$

$\mathrm{n}-$ number of criteria $=7$

Table 6. Random Index

\begin{tabular}{|c|c|c|c|c|c|c|c|c|c|c|}
\hline No & 1 & 2 & 3 & 4 & 5 & 6 & $\mathbf{7}$ & 8 & 9 & 10 \\
\hline RCI & 0.00 & 0.00 & 0.58 & 0.90 & 1.12 & 1.24 & $\mathbf{1 . 3 2}$ & 1.41 & 1.45 & 1.49 \\
\hline
\end{tabular}

From equation (3),

Consistency Ratio $=0.086101<\mathbf{0 . 1 0}$

Since we got 0.086101 i.e., $8.61 \%$ error only which is less than $10 \%$ then we have considered the criteria weights which we got from Analytical Hierarchy Process. If the error is more than $10 \%$, then we should repeat the entire AHP steps until we got the error less than $10 \%$.

Once the criteria weights are finalised, it will be used in TOPSIS method for ranking the wind power projects. 


\subsection{TOPSIS Calculations}

Table 7. Beneficial and Non-beneficial criterion values calculated using AHP

\begin{tabular}{|c|c|c|c|c|c|c|c|}
\hline Criteria & CT1 & CT2 & CT3 & CT4 & CT5 & CT6 & CT7 \\
\hline $\begin{array}{c}\text { Beneficial / } \\
\text { Non-beneficial }\end{array}$ & Benficial & Benficial & $\begin{array}{c}\text { Non } \\
\text { Benficial }\end{array}$ & $\begin{array}{c}\text { Non } \\
\text { Benficial }\end{array}$ & Benficial & Benficial & $\begin{array}{c}\text { Non } \\
\text { Benficial }\end{array}$ \\
\hline $\begin{array}{c}\text { Weight } \\
\left(W_{j}\right)\end{array}$ & $\mathbf{0 . 0 5 4 9 7}$ & $\mathbf{0 . 0 6 7 8 2}$ & $\mathbf{0 . 0 9 1 7 2}$ & $\mathbf{0 . 1 7 7 7 6}$ & $\mathbf{0 . 1 2 4 9 2}$ & $\mathbf{0 . 1 9 3 3 5}$ & $\mathbf{0 . 2 8 9 4 2}$ \\
\hline
\end{tabular}

The above table consists of weights of each criteria which we got from AHP method.

The complete data for each wind power project is given below will be used for ranking the projects using TOPSIS algorithm.

Table 8. Decision Matrix for projects

\begin{tabular}{|c|c|c|c|c|c|c|c|}
\hline Project's & CT1 & CT2 & CT3 & CT4 & CT5 & CT6 & CT7 \\
\hline WPP1 & 1064 & 120 & 1700 & 14500 & 0.21 & 15.3 & 70 \\
\hline WPP2 & 1500 & 120 & 1900 & 10500 & 4.2 & 19 & 60 \\
\hline WPP3 & 650 & 120 & 2000 & 8000 & 1.75 & 5 & 80 \\
\hline WPP4 & 150 & 120 & 1500 & 6000 & 1 & 2 & 50 \\
\hline WPP5 & 56.1 & 120 & 2500 & 4000 & 1.29 & 5 & 70 \\
\hline WPP6 & 6 & 78 & 2600 & 2000 & 0.9 & 11 & 30 \\
\hline
\end{tabular}

Table 9. Normalized matrix

\begin{tabular}{|c|c|c|c|c|c|c|c|}
\hline Project's & CT1 & CT2 & CT3 & CT4 & CT5 & CT6 & CT7 \\
\hline WPP1 & 0.5437 & 0.4294 & 0.3349 & 0.6909 & 0.0427 & 0.5513 & 0.4596 \\
\hline WPP2 & 0.7664 & 0.4294 & 0.3744 & 0.5003 & 0.8534 & 0.6847 & 0.3939 \\
\hline WPP3 & 0.3321 & 0.4294 & 0.3941 & 0.3812 & 0.3556 & 0.1802 & 0.5252 \\
\hline WPP4 & 0.0766 & 0.4294 & 0.2955 & 0.2859 & 0.2032 & 0.0721 & 0.3283 \\
\hline WPP5 & 0.0287 & 0.4294 & 0.4926 & 0.1906 & 0.2621 & 0.1802 & 0.4596 \\
\hline WPP6 & 0.0031 & 0.2791 & 0.5123 & 0.0953 & 0.1829 & 0.3964 & 0.1970 \\
\hline
\end{tabular}

Table 10. Weighted Normalized matrix

\begin{tabular}{|c|c|c|c|c|c|c|c|}
\hline Project's & CT1 & CT2 & CT3 & CT4 & CT5 & CT6 & CT7 \\
\hline WPP1 & 0.0299 & 0.0291 & 0.0307 & 0.1228 & 0.0053 & 0.1066 & 0.1330 \\
\hline WPP2 & 0.0421 & 0.0291 & 0.0343 & 0.0889 & 0.1066 & 0.1324 & 0.1140 \\
\hline WPP3 & 0.0183 & 0.0291 & 0.0361 & 0.0678 & 0.0444 & 0.0348 & 0.1520 \\
\hline WPP4 & 0.0042 & 0.0291 & 0.0271 & 0.0508 & 0.0254 & 0.0139 & 0.0950 \\
\hline WPP5 & 0.0016 & 0.0291 & 0.0452 & 0.0339 & 0.0327 & 0.0348 & 0.1330 \\
\hline WPP6 & 0.0002 & 0.0189 & 0.0470 & 0.0169 & 0.0228 & 0.0766 & 0.0570 \\
\hline
\end{tabular}

Table 11. Best value $\mathrm{V}_{i}^{*}$ and worst value $\mathrm{V}_{\mathrm{i}}^{-}$

\begin{tabular}{|c|c|c|c|c|c|c|c|}
\hline Criteria & CT1 & CT2 & CT3 & CT4 & CT5 & CT6 & CT7 \\
\hline $\boldsymbol{V}_{\boldsymbol{i}}{ }^{*}$ & 0.04213 & 0.02913 & 0.02711 & 0.01694 & 0.10661 & 0.13238 & 0.05700 \\
\hline $\boldsymbol{V}_{\boldsymbol{i}}$ & 0.00017 & 0.01893 & 0.04699 & 0.12281 & 0.00533 & 0.01394 & 0.15201 \\
\hline
\end{tabular}

Table 12. Euclidean distance from ideal best $\mathrm{Si}^{+}$and from ideal worst $\mathrm{Si}^{-}$

\begin{tabular}{|c|c|c|c|c|c|c|}
\hline Project's & WPP1 & WPP2 & WPP3 & WPP4 & WPP5 & WPP6 \\
\hline Si ${ }^{*}$ & 0.167548 & 0.092114 & 0.160137 & 0.157029 & 0.151681 & 0.111284 \\
\hline Si - & 0.100996 & 0.170016 & 0.074464 & 0.096698 & 0.097817 & 0.156445 \\
\hline
\end{tabular}


A Multi Criteria Decision Making Approach for the Selection of Optimum Location for Wind Power Project in India

Table 13. Performance Score using TOPSIS with AHP

\begin{tabular}{|c|c|c|c|c|c|c|}
\hline Project's & WPP1 & WPP2 & WPP3 & WPP4 & WPP5 & WPP6 \\
\hline $\boldsymbol{P}_{\boldsymbol{i}}$ & 0.376087 & $\mathbf{0 . 6 4 8 5 9 3}$ & 0.317407 & 0.381109 & 0.392055 & 0.58434 \\
\hline Rank & 5 & $\boldsymbol{1}$ & 6 & 4 & 3 & 2 \\
\hline
\end{tabular}

Finally, from the above table, Muppandal wind farm, Kanyakumari (WPP2) ranked the best project among six windfarms and the order of preference is as follows:

\section{WPP2(0.648593) $>$ WPP6(0.58434) $>W P P 5(0.392055)>W$ PP4(0.381109)>WPP1(0.376087) $>$ WPP3 (0.317407).} Here WPP2 is having a score of 0.648593 which is close to ideal solution i.e.1.

Here Analytical Hierarchy Process method is used to find the criteria weights, those will be used in TOPSIS algorithm to rank the projects from performance scores of all projects.

The proposed methodology for the selection of best windfarm [1,5] among six projects which are located in different places of India has done using MCDM method. After finding the performance score using different criteria's, it is observed that the Muppandal wind farm, Kanyakumari and Tirupathi windmill, Tirupathi obtained the relative closeness to ideal solution and the values are 0.5462 and 0.58434 respectively. From the results it is observed Muppandal wind farm, Kanyakumari is identified as the best wind power project among the considered ones which has the best relative closeness value since it is having high generating capacity of $1500 \mathrm{MW}$, high wind speed of $19 \mathrm{~m} / \mathrm{s}$ and it is saving the environment from $\mathrm{CO}_{2}(4.2$ million tonnes reduced).

Since TOPSIS is one of the multi criteria decision making approach, one of the best method for selecting a best site location for wind power projects, solar power project and many other purposes. I have chosen this method because it gives the best closest value to the ideal solution i.e., 1. All the steps in this method is understandable and easy to execute. So whenever any organisation or company wanted to install a wind power project, firstly they have to identify the best location for that. Not only installed power capacity, so many other factors are also they have to consider, like wind speed, amount of $\mathrm{CO} 2$ emissions can be reduced, tower height, blade length etc., For those organisations or companies this method is a reference for them to start a project to give best results.

\section{Conclusion}

It is observed that Muppandal wind farm, Kanyakumari (WPP2) ranked the best project among six windfarms with a score of 0.648593 which is having relative closeness to the ideal solution based on several criteria's. Since the TOPSIS is having more steps and calculations, the performance score is not exactly nearer to ideal solution i.e., the first ranked Muppandal wind farm, Kanyakumari having a score of 0.648593 is not relatively closeness to ideal solution 1. In order to overcome this problem, in future AHP can be integrated with VIKOR method which is having best relative closeness to ideal solution.

\section{References}

1. ARAS H. (2004), Multi-criteria selection for a wind observation station location using analytic hierarchy process, Renew Energy, 29:1383-1392.

2. LEE SK. (2009), Decision support for prioritizing energy technologies against high oil prices: a fuzzy analytic hierarchy process approach, J Loss Prev Process Ind 22:915-920.

3. CHENG EWL. (2005), Analytic network process applied to project selection, J Constr Eng Manag 131:459-466.

4. BEGIC F. (2007), Sustainability assessment tool for the decision making in selection of energy system, Bosnian case. Energy 32:1979-1985.

5. IVANOVA EY. (2005), A multi criteria approach to expansion planning of wind power plants in electric power systems, In: Power tech, 2005 IEEE Russia, 2005, pp 1-4.

6. CHARNES, A., COOPER, W. W., \& RHODES, E. (1978), Measuring the efficiency of decision making units, European journal of operational research, 2(6), 429-444.

7. HAWORTH, N. (2012), Powered two wheelers in a changing world Challenges and opportunities, Accident Analysis \& Prevention, 44(1), 12-18.

8. PAMUČAR, D., \& ĆIROVIĆ, G. (2015), The selection of transport and handling resources in logistics centers using Multi-Attributive Border Approximation area Comparison (MABAC), Expert Systems with Applications, 42(6), 30163028.

9. AMER M, \& DAIM TU. (2011), Selection of renewable energy technologies for a developing county: a case of Pakistan, Energ Sustain Dev 15(4):420-435.

10. MARTIN H, SPANO G, KÜSTER J, COLLU M \& KOLIOS A. (2013), Application and extension of the TOPSIS method for the assessment of floating offshore wind turbine support structures, Ships Offshore Struct 8(5):477-487.

11. DATTA A, SAHA D, RAY A \& DAS P. (2014), Anti-islanding selection for gridconnected solar photovoltaic system applications: a MCDM based distance approach. Sol Energy 110:519-532.

12. KAHRAMAN C \& KAYA I. (2010), A fuzzy multicriteria methodology for selection among energy alternatives, Expert Syst Appl 37(9):62706281. 